\title{
Efektifitas Video Tutorial Berbasis Smartphone Terhadap Peningkatan Pengetahuan dan Sikap Keluarga dalam Merawat Aktivity Daily Living (ADL) Pasien Gangguan Jiwa
}

\author{
$\operatorname{Irfan}^{1}$, Aswar $^{2}$ \\ ${ }^{1,2)}$ Stikes Marendeng Majene
}

\section{Keywords :}

Knowledge, attitude, schizophrenia, smartphone, video tutorial

\section{Kontak :}

Irfan

Email : irvanners@gmail.com

Stikes Marendeng Majene

DOI : https://doi.org/10.15294/

kemas.v14i3.1562

\section{(C)2020J-Healt}

ini adalah artikel dengan akses terbuka dibawah licenci CC BY-NC-4.0

https://creativecommons.org/licenses/by-nc/4.0/

\begin{abstract}
Objektive: Activity Daily Living (ADL) is the most common issue with schizophrenic patients. Schizophrenic patients need help and support from families in the fulfillment of Activities Daily Living (ADL). Providing health education to the family can increase family knowledge in the treatment process. Use of video-based media tutorials that can provide health education information through animation video demonstrations. Method: This research uses quasi experimental research method with pretest and posttest with control group approach. The research sample was 40 people of 341 members of the Schizophrenia family, who were recruited through purposive sampling and divided into 2 groups, 20 respondents in intervention group and 20 respondents control group. The knowledge of respondents was measured using instruments developed by researchers and conducted test content and construct test with the value of Cronbach's Alpha 0.954. Data analyzed using T-Test. Results : There is no meaningful difference among intervention Group (IG) and Control Group (CG). Video smartphone-based tutorial of knowledge $(I G=0,000, C G=0,000)$ and family attitude (IG=0,000,CG=0,000 in maintaining the activity daily living $(A D L)$ disorder patient. Conclusion: The conclusion of this study that the administration of health education intervention using audiovisual media video smartphone-based tutorials showed significant influence on the increased knowledge and family attitude about Activities Daily Living (ADL) in schizophrenic patients even though statistically control group get same results.
\end{abstract}




\section{PENDAHULUAN}

Skizofrenia di seluruh dunia sudah menjadi masalah yang serius. Data global menunjukkan World Health Organization (2016) jumlah penderita Skizofrenia lebih dari 21 juta orang (laki-laki:12 juta orang dan perempuan: 9 juta orang). Di Amerika Serikat sekitar 1 dari 100 orang dilaporkan memiliki gangguan skizofrenia dan lebih dari 100.000 kasus baru didiagnosa setiap tahunnya (Michelle \& Sherman, 2005). Kementerian Kesehatan RI dalam Riskesdas (2013) melaporkan jumlah penderita gangguan jiwa berat di Indonesia mencapai 1.7 per mil atau sekitar 1-2 orang per 1000 penduduk Indonesia atau sekitar 400 ribu orang.

Permasalahan utama yang dialami klien Skizofrenia adalah ketidakmampuan pasien melakukan Activities Daily Living (ADL) (Videbeck, 2008). Hasil penelitian yang dilakukan oleh Hardani, Basirun, \& Sawiji (2009) memperlihatkan dari 32 responden $100 \%$ mengalami ketidakmampuan dalam pemenuhan Activities Daily Living (ADL) dengan tingkat ketergantungan yang berbedabeda. Permasalahan pemenuhan Activities Daily Living (ADL) diakibatkan perubahan proses pikir yang menyebabkan kemunduran dalam menjalani kehidupan sehari-hari.

Intervensi pada proses pemenuhan Activities Daily Living (ADL) di Indonesia berupa pemberian pendidikan kesehatan pada keluarga masih menggunakan media-media sederhana antara lain adalah alat bantu lihat (visual), dengar (audio), dan alat bantu dengar dan lihat (audiovisual) (Notoatmodjo, 2007). Sedangkan di negara luar telah melakukan pengembangan media pendidikan kesehatan yang ditransformasi kedalam kemanfaatan fitur smartphone (Mosa, Yoo, \& Sheets, 2012). selain penggunaannya dalam komunikasi klinis mobile, apliksai smartphone juga dapat digunakan dalam pendidikan kesehatan pada pasien, manajemen diri pada penyakitnya, dan pemantauan jarak jauh dari pasien, Pemanfaatan smartphone sebagai alat medis dapat berguna dalam praktek kedokteran yang berfokus pada titik perawatan, (Mosa et al., 2012).

Penggunaan peralatan medis berbasis aplikasi smartphone memiliki potensi signifikan dalam meningkatkan efisiensi sistem perawatan kesehatan (Gaglani, 2013). Penggunaan aplikasi kesehatan smartphone juga dapat memberikan informasi pendidikan kesehatan kepada pasien dan keluarga sehingga penggunaan intervensi dapat meningkatkan manajemen diri dan perubahan perilaku kesehatan kapan dan dimanapun mereka butuhkan (Li et al., 2014). Beberapa penelitian telah memperlihatkan efektifitas penggunaan aplikasi smartphone dalam pemanfaatan media pendidikan kesehatan (Kratzke \& Cox, 2012). Hasil ini menunjukkan bahwa pemberian pendidikan kesehatan dengan menggunakan aplikasi smartphone dianggap memberikan efektifitas dalam mempermudah dan mengoptimalkan perawatan pada klien.

Penggunaan smartphone telah mengalami peningkatan yang cukup pesat khususnya di Indonesia. Data yang dikeluarkan situs Techinasia (2014) Indonesia akan melampaui 100 juta pengguna smartphone aktif pada tahun 2018, menjadikannya negara dengan populasi pengguna smartphone terbesar keempat di dunia (di belakang China, India, dan Amerika Serikat). Namun kondisi ini belum dapat dimaksimal untuk pemanfaatan media smartphone sebagai media pendidikan kesehatan dalam proses pemenuhan Activities Daily Living (ADL) pasien skizofrenia. Diharapkan pemanfaatan tehnologi dapat membantu tenaga kesehatan dalam proses perawatan pada pasien skizofrenia. Apakah dengan menggunakan aplikasi smarphone ICS_Mobile dapat meningkatkan pengetahuan keluarga tentang proses pemenuhan Activities Daily Living (ADL) pasien skizofrenia ? 


\section{METODE}

Penelitian ini menggunakan metode quasi eksperiment, dengan desain pre and post test with control group dan Rancangan penelitian ini melibatkan satu kelompok perlakuan dan kontrol serta melakukan pengkajian sebelum dilakukan pemberian intervensi untuk dapat menguji perubahan-perubahan yang terjadi setelah adanya intervensi. Populasi dalam penelitian ini adalah adalah seluruh keluarga pasien yang mengalami gangguan skizofrenia di Wilayah Kerja Puskesmas Kabupaten Majene sebanyak 341 klien. Teknik pengambilan sampel menggunakan Non probability sampel dengan metode purposive sampling, dengan jumlah sampel 40 keluarga (20 kelompok kontrol dan 20 kelompok intervensi) dengan kriteria inklusi keluarga yang merawat pasien skizofrenia dan tinggal serumah dengan klien, keluarga yang memiliki smartphone, dan berlatar belakang pendidikan minimal lulsan SMP. Sedangkan kriteria eksklusinya adalah keluarga yang mengalami gangguan penglihatan dan pendengaran, dan keluarga yang buta huruf.

Tempat penelitian ini dilaksanakan di Wilayah Kerja Puskesmas Kabupaten Majene Provinsi Sulawesi Barat dan Instrumen pengetahuan dan sikap keluarga tentang penatalaksanaan perawatan activities daily living (ADL) dibuat oleh peneliti berdasarkan tinjauan teoritis tentang perawatan activities daily living (ADL) di rumah yang terdiri dari kemampuan kognitif mengingat, memahami, dan mengaplikasikan dengan butir jawaban yaitu (benar dan salah). Penilaian pengetahuan dan sikap tentang ADL berupa kuesioner yang mencakup pengetahuan tentang konsep ADL pasien skizofrenia, kebersihan diri, berpakaian/berhias, Makan \& Minum, dan Eliminasi, Instrumen ini telah dilakukan uji validitas content kepada expert dosen ahli pendidikan keperawatan jiwa dan uji validitas menunjukkan terdapat 25 soal yang valid dengan nilai realiabilitas AlphaCronbach 0,94.

Jenis penelitian yang digunakan dalam penelitian ini adalah deskriptif analitik, dengan pendekatan Cross-Sectional merupakan suatu penelitian yang mempelajari hubungan antara faktor risiko (indpenden) dengan faktor efek (dependen) dimana di lakukan observasi atau pengukuran variable sekali dan sekaligus pada waktu yang sama (Agus, 2011). Penelitian dilakukan di SMPN 4 Majene Kecamatan Banggae Kabupaten Majene. Populasi dan sampel adalah seluruh remaja putri kelas 2 dan kelas 3 sebanyak 47 orang

Teknik pengambilan sampel dalam penelitian ini adalah teknik non probability sampling dengan pendekatan purposive sampling yaitu pengambilan sampel yang didasarkan atas pertimbangan dan sesuai dengan kriteria inklusi dan eksklusi. Analisis yang digunakan dalam penelitian ini yaitu analisis univariat dan analisis bivariat dengan menggunakan uji statistik Chi Square

\section{HASIL}

\section{Tabel 1}

Perbedaan Perubahan Rata-rata Skor Tingkat Pengetahuan dan sikap Keluarga Tentang Activities Daily Living (ADL) Sebelum dan Sesudah Mendapatkan Perlakuan pada Kelompok Intervensi $(\mathrm{N} 1=20, \mathrm{~N} 2=20)$.

\begin{tabular}{lccc}
\hline $\begin{array}{l}\text { Kelompok } \\
\text { Intervensi }\end{array}$ & Pretes & Postes & $\begin{array}{c}\boldsymbol{p} \\
\text { value }\end{array}$ \\
\hline Pengetahuan & 15.80 & 23.25 & 0.000 \\
\hline Sikap & 23.65 & 46.10 & 0.000 \\
\hline
\end{tabular}

Studi ini menemukan nilai hasil skor rata-rata pengetahuan kelompok intervensi pada pengukuran awal sebelum dilakukan perlakuan diperoleh nilai rata-rata skor pengetahuan 15.80 dan setelah pemberian media video tutorial nilai rata-rata scor pengetahuan mengalami peningkatan menjadi 23.25, hasil ini menunjukan perbedaan peningkatan skor pengetahuan setiap pemberian intervensi menggunakan media video tutorial dengan melakukan analisis uji $T$-test didapatkan nilai $p=$ value $0,000<0,05$. Sedangkan hasil skor rata-rata sikap kelompok intervensi pada pengukuran awal sebelum dilakukan perlakuan diperoleh nilai 
rata-rata skor pengetahuan 23.65 dan setelah pemberian media video tutorial nilai rata-rata scor pengetahuan mengalami peningkatan menjadi 46.10, hasil ini menunjukan perbedaan peningkatan skor sikap setiap pemberian intervensi menggunakan media video tutorial dengan melakukan analisis $u j i$ $T$-test didapatkan nilai $p=$ value $0,000<0,05$.

Tabel 2

Perbedaan Perubahan Rata-rata Skor Tingkat Pengetahuan dan Sikap Keluarga Tentang Activities Daily Living (ADL) Sebelum dan Sesudah Mendapatkan Perlakuan pada Kelompok Kelompok Kontrol $(\mathrm{N} 1=20, \mathrm{~N} 2=20)$

\begin{tabular}{lccc}
\hline $\begin{array}{c}\text { Kelompok } \\
\text { Kontrol }\end{array}$ & Pretes & Postes & p value \\
\hline Pengetahuan & 12.90 & 15.60 & 0.000 \\
\hline Sikap & 23.95 & 31.95 & 0.000 \\
\hline
\end{tabular}

Studi ini menemukan nilai hasil skor rata-rata pengetahuan kelompok kontrol pada pengukuran awal sebelum dilakukan perlakuan diperoleh nilai rata-rata skor pengetahuan 15.80 dan setelah pemberian leaflet nilai rata-rata scor pengetahuan mengalami peningkatan menjadi 23.25 , hasil ini menunjukan perbedaan peningkatan skor pengetahuan setiap pemberian intervensi menggunakan media video tutorial dengan melakukan analisis uji T-test didapatkan nilai $p=$ value $0,000<0,05$. Sedangkan hasil skor rata-rata sikap kelompok intervensi pada pengukuran awal sebelum dilakukan perlakuan diperoleh nilai rata-rata skor pengetahuan 23.65 dan setelah pemberian media leaflet nilai rata-rata scor pengetahuan mengalami peningkatan menjadi 46.10, hasil ini menunjukan perbedaan peningkatan skor sikap setiap pemberian intervensi menggunakan leaflet dengan melakukan analisis uji T-test didapatkan nilai $p=v a l u e$ $0,000<0,05$.

\section{Diagram 1 \\ Perbedaan Perubahan Rata-Rata Skor \\ Perubahan Pengetahuan Keluarga Tentang Activities Daily Living (ADL) Antara \\ Kelompok Perlakuan Dan Kelompok Kontrol $(\mathrm{N} 1=20, \mathrm{~N} 2=20)$}

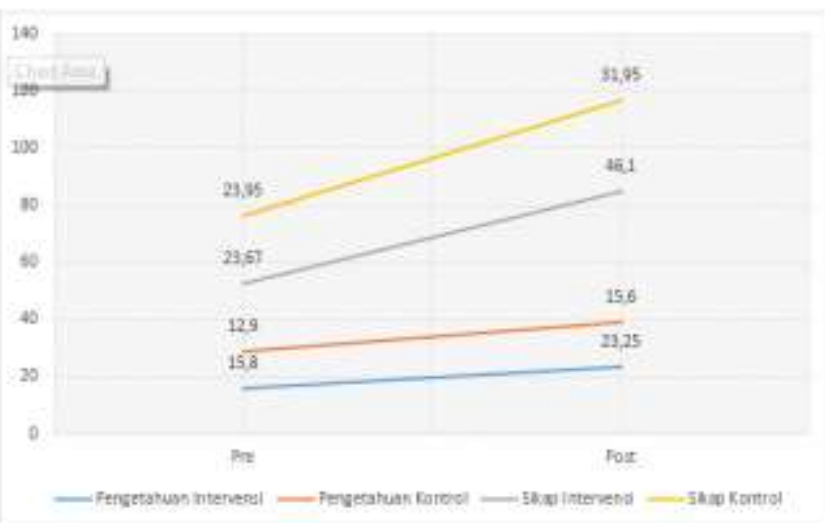

Studi ini menemukan hasil perbedaan ratarata skor pengetahuan sebelum dan setelah intervensi pada kelompok kontrol dan perlakuan dengan malakukan analisis uji independent $t$ test yang menunjukkan pada kedua hasil pengukuran akhir terdapat perbedaan bermakna dengan nilai $p=v a l u e$ 0,000 . Sedangkan hasil hasil perbedaan ratarata skor sikap sebelum dan setelah intervensi pada kelompok kontrol dan perlakuan dengan malakukan analisis uji independent $t$ test yang menunjukkan pada kedua hasil pengukuran akhir terdapat perbedaan bermakna dengan nilai $p=$ value 0,000 .

\section{PEMBAHASAN}

Penelitian ini menunjukkan hasil bahwa pada kelompok intervensi yang menggunakan video tutorial sebagai media pendidikan kesehatan efektif dan dapat diaplikasikan pada keluarga pasien skizofrenia dalam proses pemenuhan activities daily living (ADL). Proses peningkatan pengetahuan dan sikap keluarga setiap pengukurannya memperlihatkan grafik yang terus meningkat disetiap proses penggunaan video tutorial sebagai media pendidikan kesehatan.

Efektifitas terlihat pada pemberian pendidikan kesehatan menggunakan video tutorial yang berisi informasi proses perawatan activities daily living (ADL) pada pasien skizofrenia 
dengan memunculkan Audiovisual melalui video. Hal ini sejalan dengan teori Cognitive Theory of Multimedia Learning (CTML) dalam Mayer (2004) menyatakan bahwa multimedia dalam proses pemberian informasi mampu mengkombinasikan berbagai jenis media termasuk teks, gambar, suara dan video sehingga meningkatkan retensi pengetahuan seseorang. pemberian informasi kesehatan yang dirancang dengan baik sesuai dengan sasaran yang ingin dicapai dapat merubah proses pikir yang dipengaruhi oleh peningkatan pengetahuan dan kesadaran yang telah diterima dari pendidikan kesehatan (Onono et al., 2014).

Efektifitas penggunaan media video tutorial dalam meningkatkan pengetahuan dan sikap keluarga dapat memandirikan keluarga dalam proses perawatan activities daily living (ADL). Mosa et al., (2012) mengungkapkan bahwa penggunaan smartphone dalam pemberian informasi berupa pendidikan kesehatan pada pasien dan keluarga dapat meningkatkan kemampuan pasien dalam manejemen diri secara mandiri pada perawatan penyakitnya dan pemantauan jarak jauh pada pasien. Penelitian yang dilakukan oleh Kim, Shin, Lee, Kang, \& Bartlett, (2017) menunjukkan hasil bahwa pendidikan berbasis tehnologi dapat menjadi metode yang efektif untuk digunakan dalam pendidikan keperawatan. Hal ini menunjukkan bahwa pemberian pendidikan kesehatan dengan menggunakan tehnologi dianggap memberikan efektifitas dalam mempermudah dan mengoptimalkan perawatan pada klien.

Dari hasil perbedaan penggunaan media pada kelompok intervensi penggunaan media video tutorial dengan kelompok kontrol yang menggunakan media leaflet dalam meningkatkan pengetahuan dan sikap memperlihatkan hasil terdapat perbedaan bermakna dengan nilai $\mathrm{p}=$ value 0,000 .

Perbedaan pemberian informasi kesehatan akan dipengerahui oleh metode yang digunakan, pemberian edukasi kesehatan yang hanya berfokus pada pengajaran saja dianggap belum mampu meningkatkan outcome pasien. ( kauric-klien,2011). penelitian Kholik (2014) yang mendapatkan hasil bahwa pemilihan media bergambar hidup atau adiovisual dengan belajar prinsip, konsep dan aturan didapatkan hasil pemahaman yang tinggi dari informasi yang diberikan, sedangkan pada media yang hanya bergambar diam atau visual mendapatkan hasil pemahaman sedang dari informasi yang diberikan.

\section{KESIMPULAN}

Kesimpulan dari penelitian ini bahwa pemberian intervensi pendidikan kesehatan menggunakan media video tutorial menunjukkan pengaruh yang signifikan terhadap peningkatan pengetahuan dan sikap keluarga tentang activities daily living (ADL) pada pasien Skizofrenia.

Intervensi pendidikan kesehatan menggunakan video tutorial diharapkan menjadi bahan pertimbangan khusus bagi pelayanan kesehatan sebagai salah satu media pendidikan kesehatan yang dapat diterapkan dalam merawat klien skizofrenia yang mendapat perawatan di rumah dengan memfokuskan peningkatan pengetahuan keluarga dalam merawat pasien skizofrenia. Penelitian selanjutnya disarankan dapat melihat efektifitas video tutorial terhadap sikap dan perilaku dalam proses perawatan activities daily living (ADL) serta dapat mengembangkan aplikasi berbasis kolaborasi dengan pemberian pengobatan melalui intruksi dokter.

\section{UCAPAN TERIMA KASIH}

Pada kesempatan ini peneliti mengucapkan banyak terimakasih pada keluarga klien skizofrenia yang telah bersedia menjadi partisipan/responden dalam penelitian, sehingga peneliti dapat menyelesaikan penelitian ini, Tenaga perawat di yang bertugas di Wilayah Kerja Puskes Kabupaten Majene yang telah membantu dalam proses administrasi sampai proses pengambilan data serta kepada KEMENRISTEK DIKTI yang telah memberikan bantuan dana dalam proses penelitian. 


\section{DAFTAR PUSTAKA}

APJII.

(2016). Buleting

Asosiasi

Penyelenggara JasaInternet Indonesia (APJII), 2-6. Retrieved from http://mkekpbidi.org/wpcontent/uploads/2016/01/PEDOMANORG-TATAKERJAMKEK.pdf

Chinwe R, E. (2015). Impact of Health Education on Knowledge, Attitude and Practice of Cervical Cancer Screening Among Secondary School Teachers in Enugu State. Journal of Womens Health Care, 04(04).

https://doi.org/10.4172/21670420.1000241

Balitbang Kemenkes RI. (2013). Riset Kesehatan Dasar; RISKESDAS. Jakarta: Balitbang Kemenkes RI

Brunner and Suddarth. (2002). Buku Ajar Keperawatan Medikal Bedah, edisi 8 volume 2. Jakarta : EGC.

Fitriani, (2010). Jurnal Hubungan Pendidikan Ilmiah Volume Ii1 No. 2 . Jakarta.

Gaglani, M. A. B. and S. M. (2013). Virtual Mentor. AMA Journal of Ethics ${ }^{\circledR}$ Illuminating the Art of Medicine, 15(11), 947-950. Retrieved from http://journalofethics.amaassn.org/2013/0 5/ecas3-1305.html

Jackson, J. (2016). Myths of Active Learning : Edgar Dale and the Cone of Experience. Journal of the Human Anatomy and Physiology Society, 20(2), 51-53.

Kapti, R.E. (2010). Efektivitas audiovisual sebagai media penyuluhan kesehatan terhadap peningkatan pengetahuan dan sikap ibu dalam tatalaksana balita dengan diare di dua rumah sakit kota malang.Tesis. FIK UI: Depok.

Keliat, B.A, dkk. (2011). Keperawatan Kesehatan Jiwa Komunitas: CMHN (Basic Course). Jakarta: EGC

Liana, L. (2015). Pengaruh pendidikan kesehatan dengan audiovisual tentang hiv/aids terhadap pengetahuan dan sikap remaja kelas x smk n 1 bantul.

Michelle, \& Sherman. (2005). Session Four Schizophrenia and its Impact on the Family, 74-84.

Mosa, A. S. M., Yoo, I., \& Sheets, L. (2012). A systematic review of healthcare applications for smartphones. BMC Medical Informatics and Decision Making, $\quad 12(1), \quad 67$. https://doi.org/10.1186/1472-6947-12-67

Montano, D. E., \& Kasprzyk, D. (2008). HEALTH BEHAVIOR AND HEALTH EDUCATION. Health Behavior and Health Education: Theory Research \& Practice. https://doi.org/10.1016/S00333506(49)81524-1

Notoatmodjo , S. (2011). Kesehatan Masyarakat Ilmu dan Seni. Penerbit Rineka Cipta. Jakarta.

Sadiman, Arief S. dkk . (2008). Media Pendidikan Pengertian, Pengembangan, dan Pemanfaatannya. Jakarta: Pustekkom Dikbud dan PT.Raja Grafindo Persada

Uno, Hamsah B. 2014. Model Pembelajaran Menciptakan Proses Belajar Mengajar yang Kreatif dan Efektif. Jakarta: Bumi Aksara

World Health Organization. (2016). Nurse educator core competencies. Retrivied from:

http://ww.who.int/hrh/nursing_midwifer/n urse_educator050416.pdf

Williams, Brie (2014). "Consideration of Function \& Functional Decline". Current Diagnosis and Treatment: Geriatrics, Second Edition. New York, NY: McGraw-Hill. pp. 3-4. ISBN 978-0-07179208-0. 